\title{
ASSISTÊNCIA HUMANIZADA AO CLIENTE ONCOLÓGICO: reflexões junto à equipe
}

\author{
Cleonice Antonieta Costa* \\ Wilson Danilo Lunardi Filho** \\ Narciso Vieira Soares ${ }^{\star \star *}$
}

\section{Resumo}

O presente relato refere-se a uma prática assistencial, construída e implementada junto a membros da equipe de saúde de um Serviço de Oncologia e Radioterapia de um hospital geral de grande porte da região leste do Rio Grande do Sul, visando à humanização da assistência. Constituiu-se numa possibilidade de refletir com a equipe de trabalho, acerca da assistência prestada aos clientes à luz das propostas do Sistema Único de Saúde (SUS) e sob a ótica da abordagem humanística e suas propostas metodológicas.

Descritores: enfermagem oncológica; educação; equipe de enfermagem; ética

\section{Abstract}

The present study is concerning a practice of assistance built and implemented with the health team members of an Oncology and Radiotherapy Service in a large general hospital in the east part of the state of Rio Grande do Sul, attempting to make the assistance more humane. It was a possibility of reflecting with the work team about the assistance provided to the patients in light of the proposals of SUS (New Public Health System) and with the perspective of the humanistic approach and its methodological proposals.

Descriptors: Oncology nursing; Education; Nursing Team; Ethics

Title: Humanized assistance with an oncology patient: reflections with the health team

\section{Resumen}

El presente texto se refiere a una práctica asistencial, construida e implementada junto al equipo de salud de un Servicio de Oncología y Radioterapia de un hospital general de grandes proporciones en la región leste de Rio Grande do Sul, cuyo objetivo es la humanización de la asistencia. El trabajo aportó la posibilidad de reflexionar con el equipo de trabajo sobre la asistencia que se da a los clientes, a la luz de las propuestas del Sistema Único de Salud (SUS) y bajo la óptica humanística y sus propuestas metodológicas. Descriptores: Enfermería Oncológica; Educación; Equipo de Enfermería; Ética

Título: Asistencia humanizada al cliente oncológico: reflexiones junto al equipo

\section{Introdução}

Cada vez mais, vivencia-se o aumento significativo das neoplasias malignas. No quadro sanitário brasileiro, esta realidade tem ampliado a discussão sobre o controle desse grupo de doenças, incluindo-as como uma das prioridades em saúde. Apesar de ainda haver áreas obscuras na compreensão da etiologia do câncer, já se tem conhecimentos suficientes para embasar ações de controle capazes de diminuir a sua incidência e mortalidade.

A possibilidade de cura do câncer, na maioria de suas formas, está diretamente relacionada à sua extensão, quando é instituído o primeiro tratamento, assim como a qualidade e disponibilidade dos recursos para tratá-lo. No Brasil, as doenças crônico-degenerativas, entre elas o câncer, vêm recebendo atenção caracterizada por ações essencialmente terapêuticas, de alta tecnologia e alto custo, dirigidas a pacientes com doenças sintomáticas e, na maioria das vezes, avançadas. Esta situação, com freqüência é agravada pela falta de definição sobre o caminho a ser seguido pelo paciente, desde a primeira queixa até a confirmação do diagnóstico e o início do tratamento especializado.

Assim, a assistência ao paciente oncológico dá mostras de sua complexidade, pois precisa envolver a consideração de múltiplos aspectos, tais como: físicos, psicológicos, sociais, culturais, espirituais e econômicos, bem como os preconceitos e tabus existentes, pois a palavra câncer, ainda, vem carregada da idéia de maldição e morte. Como a maioria dos pacientes tem confirmado o seu diagnóstico somente em fase avançada, além da cura de muitos tipos de câncer ainda não ser possível e como o quadro que grande parte dos pacientes apresenta geralmente, é doloroso de se ver e acompanhar, os subterfúgios aumentam, decorrendo daí o emprego de termos substitutos ou sinônimos: "a doença ruim", "aquela doença", "tumor", "neo", dentre tantos outros. Ao ser abordada a questão do câncer como uma perspectiva de finitude, pode-se afirmar que se mostra tão ameaçador porque representa não apenas uma ameaça de morte, mas uma tríplice ameaça: de dor física, de mutilação e de morte $^{(1)}$

\section{A equipe e a assistência ao cliente com câncer}

O paciente com câncer não deve ser considerado, apenas, como mais um caso. Nessa perspectiva, precisa ser empreendida uma visão holística e multidisciplinar, buscando compreendê-lo nas suas múltiplas relações para proporcionar uma abordagem profissional humanizada profundamente solidária, geradora não só de saúde, mas, principalmente, de $v$ ida $^{(2)}$. Os profissionais que trabalham em oncologia estão expostos, no seu dia-a-dia de trabalho, a situações geradoras de conflitos. Os fatores que predispõem aos conflitos são, dentre outros, as freqüentes perdas por morte; as pressões que expõem o modelo médico tradicional de responsabilidade em relação à cura e à longevidade; o trabalho constante com doenças graves e com a tristeza dos familiares, o contato freqüente com os familiares e paciente, levando à criação de vínculo com maior envolvimento com o problema vivido(3).

Não raro surge o sentimento de impotência do profissional diante da doença, principalmente em sua fase terminal, que pode traduzir-se em revolta ou em abatimento. De

* Enfermeira da Unidade de Oncologia da A.C.S.C do Rio Grande e da Rede Básica de Saúde do Município do Rio Grande/RS, Especialista em Projetos Assistenciais de Enfermagem, Docente do Curso Profissionalizante de Técnico de Enfermagem do SENAC. Membro do Núcleo de Estudos e Pesquisas em Saúde - NEPES/FURG.

** Enfermeiro, Professor Adjunto IV do Departamento de Enfermagem da Fundação Universidade Federal do Rio Grande, Doutor em Enfermagem, Membro do Núcleo de Estudos e Pesquisas em Saúde - NEPES/FURG

*** Enfermeiro, Professor do Curso de Enfermagem da Universidade Regional Integrada do Alto Uruguai e das Missões - Campus Santo Ângelo, Mestre em Enfermagem, Membro do Grupo de Estudos e Pesquisas em Enfermagem, Saúde e Educação - GEPESE/URI.

Email dos autores: lunardifilho@terra.com.br; nvsoares@urisan.tche.br 
suma importância e, provavelmente, a mola mestra que vai mobilizar toda a assistência emocional que será prestada ao paciente com câncer e sua família, é a forma como a equipe comunica-se e interage com eles. A comunicação, portanto, não deve ser vista, apenas, como um processo de transmissão de informações, mas compreendida como uma possibilidade de entendimento entre as pessoas ${ }^{(4)}$. Desse modo, pode ser considerada como sendo um dos elementos fundamentais no processo de autonomia do ser humano(5).

Considera-se de grande ajuda, neste sentido, a interação multiprofissional, tendo clara a possibilidade de visualizar o cliente como um todo, nos seus aspectos bio-psico-sócioespirituais, pois o cuidado à saúde transcende o simples ato de assistir centrado no fazer, nas técnicas ou nos procedimentos; significa, também, reconhecer os clientes e seus familiares como seres humanos singulares, vivenciando um difícil momento de suas vidas.

\section{Humanizando a assistência ao cliente oncológico e sua família}

A assistência humanizada ao paciente com câncer e seus familiares consiste no emprego de atitudes que originem espaços que permitam a todos verbalizar seus sentimentos e valorizá-los; identificar áreas potencialmente problemáticas; auxiliá-los a identificar fontes de ajuda, que podem estar dentro ou fora da própria família; fornecer informações e esclarecer suas percepções; ajudá-los na busca de soluções dos problemas relacionados ao tratamento; instrumentalizá-los para que tomem decisões sobre o tratamento proposto; e levar ao desempenho de ações de auto-cuidado, dentro de suas possibilidades. Entre as múltiplas ações de saúde necessárias para propiciar cuidados que privilegiem, dentre outros, os aspectos psicológicos, estão à disponibilidade ${ }^{\mathrm{a}}$, a atitude de aceitação e de escuta e a criação e a manutenção de um ambiente terapêutico(6).

A partir dessa compreensão e diante da importância atribuída a uma assistência humanizada aos clientes, o que se pretendeu com a realização deste estudo foi construir e implementar uma prática assistencial junto à equipe de trabalho do serviço de oncologia de uma instituição hospitalar de grande porte da região leste do Rio Grande do Sul, fundamentada na Teoria Humanística, visando a humanização da assistência aos clientes ali atendidos.

\section{Caminho metodológico}

Este estudo teve como eixo norteador o processo de diálogo reflexivo junto à equipe dessa unidade de oncologia. Caracteriza-se como uma prática assistencial, que buscou construir uma proposta de assistência humanizada aos clientes por ela atendidos. Apoiando-se no referencial da enfermagem fenomenológica ${ }^{b}$, teve o diálogo como meio facilitador do intercâmbio de saberes enfermeira/equipe, visando sua instrumentalização para prestar uma assistência ao cliente como sujeito do cuidado(7). $^{(7)}$

A opção pelo trabalho com a equipe deveu-se ao fato de considerar-se que, a partir de encontros para discussões e reflexões, podem-se transformar comportamentos para prestar uma assistência com qualidade e de forma abrangente para,

\footnotetext{
a Colocar-se à disposição, durante todo o tempo em que se está com o paciente, implica comprometer-se com ele, ou seja, interessar-se e preocupar-se pela sua pessoa, evitando, porém, que se origine e desenvolva-se um comportamento de dependência.

${ }^{\mathrm{b}} \mathrm{A}$ enfermagem fenomenológica ou humanística preocupa-se com a experiência vivida pelos indivíduos como fenômenos próprios de suas vidas, os quais têm possibilitado a existência de escolhas, permanentemente, de modo que são responsáveis por suas vidas e seu desenvolvimento.
}

assim, colaborar para a melhoria da qualidade de vida dos clientes. A cada um dos participantes foi solicitado o consentimento livre e esclarecido, conforme determina a resolução 196/96 do Ministério da Saúde, bem como o Código de Ética dos Profissionais de Enfermagem. Para garantir o anonimato e o sigilo das informações, foi sugerido aos participantes adotarem nomes de flores. Assim, cada membro do grupo espontaneamente escolheu aquela de sua preferência para identificar-se: Violeta, Amor Perfeito, Lírio, Orquídea, Bemme-quer, Cravo, Girassol e Rosa.

Os encontros foram realizados em uma das salas da unidade de oncologia, em ambiente confortável, claro e arejado, sendo possível visualizar o verde da natureza, através das janelas, e tendo o canto dos pássaros como fundo musical, constituindo-se em um respiradouro para os membros do grupo. Ocorreram uma vez por semana, às sextas-feiras, devido ao menor fluxo de clientes, totalizando oito encontros com a duração aproximada de uma hora. Os diálogos foram captados em fitas magnéticas numeradas, transcritas e digitadas, contemplando as falas utilizadas pelos sujeitos com a linguagem com a qual cada um expressou suas crenças, seus valores e opiniões, acerca da assistência prestada aos clientes $^{(8)}$.

\section{Operacionalização da prática assistencial}

A experiência vivenciada resultou desse processo dialógico com oito membros da equipe de trabalho da unidade de oncologia, sujeitos desta prática assistencial, cujas cinco fases da enfermagem fenomenológica foram relacionadas aos seguintes passos do processo de enfermagem: Investigação - coleta de dados subjetivos e objetivos sobre e com a equipe, por meio do diálogo, da observação das reações e expressões de cada um dos participantes e da sua interação com o grupo. Foi possível conhecer opiniões, acerca da assistência que vêm prestando aos clientes, dúvidas, anseios e expectativas. Esta compreensão intuitiva do outro é necessária porque "a enfermeira tem que fazer uso da sua intuição como pessoa e como profissional para saber como agir da melhor forma possível em determinadas situações ${ }^{(9)}$; Diagnóstico - elaborado através do diálogo, do conhecimento de si e do outro, com a participação de todos os sujeitos desse processo. A partir da constatação das necessidades do grupo, dos problemas vividos, foi possível elaborar um plano de cuidados; Planejamento e Implementação - descrição das metas a serem atingidas, conforme os objetivos definidos junto com o grupo. As metas de bem-estar ou de vir-a-ser foram atingidas pelo diálogo, através do encontro e da presença da enfermeira com a equipe. Foi estabelecido como objetivo a ser atingido o fortalecimento do grupo, visando a humanização da assistência aos clientes atendidos na unidade; e Avaliação - ocorreu ao longo do desenvolvimento da prática assistencial, quando, ao final de cada encontro, era realizada uma avaliação, no sentido de identificar se houve ou não possíveis mudanças no comportamento dos membros da equipe, em relação à prática cotidiana e a percepção de necessidades de alterações na prática assistencial, dentre outros.

\section{Descrevendo os encontros e as reflexões emergentes}

A partir da instrumentalização inicial, mediante leituras e aprofundamento teórico, consolidou-se a preparação para conhecer os outros. O primeiro contato com o grupo visou o conhecimento subjetivo e objetivo de seus membros. Neste encontro inicial, compareceram sete dos oito integrantes do grupo, quando foi explicitado, novamente, o objetivo dessa prática assistencial, deixando claro que a sua realização só seria possível com a participação ativa de cada um. Alguns mostraram-se ansiosos e inibidos, diante da gravação das suas falas. Buscou-se, então, estabelecer, inicialmente, um diálogo descontraído, visando deixá-los mais à vontade para expressarem suas opiniões. 
Dentre os assuntos discutidos, estão àqueles relativos à importância das reuniões da equipe, percebidas como espaços para o diálogo, troca de idéias, experiências, discussão e reflexão acerca dos assuntos relativos à sua prática cotidiana. Refletindo-se sobre a importância das reuniões e o seu potencial de fortalecimento da equipe para alcançar os objetivos de humanização da assistência ao paciente oncológico, partiu-se do pressuposto de que todos podem contribuir com suas idéias e opiniões para a solução de problemas. Essa característica essencial do trabalho em equipe faz com que as chances de êxito na resolução dos problemas sejam maiores ${ }^{(10)}$. Em outras palavras, as reuniões não devem ser realizadas, apenas, para a cobrança do cumprimento de normas e rotinas da unidade ou para criticar o que está errado, mas devem servir para, a partir da identificação dos problemas, levantar sugestões, visando chegar a soluções mais concretas. Também, devem ser realizadas para elogiar, quando a equipe desempenha seu trabalho com qualidade.

Assim, pode-se perceber que o trabalho em equipe pode liberar a criatividade e a energia. As comunicações em equipes eficazes são, automaticamente, interativas; as pessoas desenvolvem-se por meio das sugestões de outras, acrescentando novas perspectivas que fazem com que a discussão evolua(11). Estas assertivas estão contempladas nas reflexões sobre a importância do diálogo com o grupo, sobre o seu fazer com uma perspectiva de melhoria na qualidade da assistência ao cliente oncológico, caracterizadas pela seguinte fala:

O mais importante é que, através dessas reuniões, está se construindo uma proposta de trabalho como início de um processo maior, onde irá se desenvolver maior união entre o grupo. Esta união só vem em benefício do paciente, pois, à medida que cada um ajudar o outro, melhor será o trabalho da equipe (Cravo).

Houve o consenso de que a equipe já vinha prestando uma assistência com bastante qualidade, embora reconheçam que sempre se pode melhorar, ou seja, podemos buscar sempre "sermos mais", em nossas atividades cotidianas, complementada pelo entendimento de que a assistência humanizada corresponde a uma forma ideal para tratar os clientes. A gente mostra que devemos tratar o paciente com respeito e não passando, para ele, a impressão de que temos pena dele (Cravo).

Refletindo acerca da prática assistencial proposta e do fazer cotidiano, em relação à humanização da assistência ao cliente oncológico, também houve o consenso que é

Um direito do cliente ser bem atendido, implicando reconhecê-lo como sujeito e não como um mero objeto. [...] O que nos falta é o que a enfermeira está nos propondo, de uma forma bastante inteligente, ou seja, instrumentalizarmo-nos melhor, visando assistir melhor.[...] temos que fazer exercícios, parar e refletir, pois isto é uma situação bastante nova. Tratarmos as pessoas com humanidade não deve ser novo, não deveria ser novidade e sim uma rotina em nossa prática profissional. Mas, como medir, como identificar esta atuação da equipe, frente às pessoas, bem como sentir isto como nós estamos sentindo, discutindo de uma forma coletiva? A realidade nos coloca em cheque, no dia a dia, questões bem complexas (Girassol).

Uma questão vivenciada freqüentemente em oncologia é a possibilidade da ocorrência e do pressentimento constante de morte a que estão submetidos os clientes e familiares. Nesse sentido, surgiu o consenso de que se deve levar em conta não somente suas necessidades biológicas, mas, principalmente, suas necessidades espirituais decorrentes dessa situação.

Eu acho que a gente falha com a assistência, quando se trabalha visando, apenas, a questão material, vendo o cliente como uma fonte de lucro, quando não se trabalha a questão espiritual do ser humano. Eu percebo, em toda a equipe, essa disponibilidade, essa boa vontade (Girassol).

Por sua vez, os pacientes que vivenciam a possibilidade de ocorrência da morte, muitas vezes, imaginam-se na iminência de "perder tudo e todos que amam"(12:93). Frente a esta possibilidade, pacientes e familiares recorrem à religiosidade para superarem esse difícil momento de suas vidas. É necessário, portanto, que a equipe reconheça a importância de fazer-se presente e atender também as necessidades religiosas dos pacientes, conforme as especificidades de sua religião, em qualquer momento, [pois] não só é uma necessidade como um direito do paciente ${ }^{(13)}$. A proximidade da morte não deve implicar o afastamento dos membros da equipe de saúde tanto do próprio cliente como dos seus familiares ${ }^{(12)}$.

Reportando-se a esta última fala, houve o questionamento sobre que estratégias poderiam ser adotadas, no sentido de evitar atitudes desumanizantes, impessoais, visualizando o paciente, apenas, como fonte de lucro. Com o objetivo de incentivar o debate, foram trazidas, então, algumas reflexões sobre a natureza humana dos membros da equipe e, por isso, ser impossível assumir uma postura, apenas, de indiferença frente aos clientes, mas capaz de olhar para suas existências, reconhecer suas unicidades, dando significado às suas experiências e à sua busca de "ser mais". Outro assunto que emergiu refere-se à união do grupo como resultado para o melhor atendimento ao cliente. O relato, a seguir, reforça a importância desta união como fator facilitador para a prestação do cuidado, dentro de uma visão humanística.

A gente pode ver qual a dificuldade do colega. Numa passada de olhos, verificar se está necessitando de ajuda. Isto pode vir em benefício de todos, pois demonstra que estamos, neste grupo, tentando fazer o melhor trabalho possível. Quando a gente se predispõe a fazer alguma coisa, tem que se fazer com carinho, tem que ter a honestidade, a solidariedade como princípios norteadores (Cravo).

A equipe, também, necessita de cuidados especiais, de atenção, visando mantê-la forte e unida, pois, quando não dispõe da ajuda necessária para se proteger dos riscos do trabalho nem para usufruir recompensas, todo o tipo de problema pode surgir como reuniões incômodas e destrutivas e o sentimento de decepção ou desmotivação(11) , cujos reflexos podem implicar baixa qualidade da assistência prestada. Refletindo-se sobre o cuidado da própria equipe como uma exigência para cuidar dos outros, foi evocado um estudo que buscou obter respostas a como se dá a governabilidade na enfermagem, abordando o cuidado de si como exigência para o cuidado do outro(14). Isto porque, para os membros da equipe reconhecerem no paciente um ser humano e assim tratá-lo, precisam, também e num estágio anterior, reconhecer-se e tratar-se como seres humanos. Como podemos falar em humanização do paciente se, antes, não podemos constatar a presença de equipes [...] humanizadas $^{(15)}$ ?

O diálogo vivo e o entrosamento entre os membros da equipe podem ser considerados como um fenômeno que envolve a nutrição do bem-estar e do mais-ser ${ }^{(7)}$. Esta transação intersubjetiva entre a equipe se dá num evento vivo experienciado pelos participantes. A partir dessa prática assistencial, houve maior interação entre eles e esta passou a ser, cada vez mais, constante no seu cotidiano, como o atesta a seguinte fala.

Apesar de trabalhar, há alguns anos, com pacientes oncológicos percebi que houve um maior entrosamento entre a equipe, principalmente, com os pacientes, procurando atendê-los melhor, dispensando mais atenção, priorizando as suas necessidades de verbalizar suas dúvidas, em relação à doença (Orquídea). 
Assim, percebe-se que a assistência humanizada inclui o estar junto de forma empática, ouvir, buscar a compreensão de necessidades, resgatando o entendimento de uma situação existencial que transcenda ao somente assistir, dentro de uma visão tradicional( ${ }^{(9)}$, provando com isso que, por mais que seja feito, sempre se pode fazer melhor. Portanto, quanto mais conseguimos incluir de nós mesmos, mais conseguimos estar abertos aos outros. Quanto mais conseguimos estar junto aos outros, mais nos permitimos compartilhar com eles ${ }^{(16)}$.

As discussões acerca do fazer cotidiano e a opção por uma assistência humanizada, como conseqüente ampliação da perspectiva do cuidado, vendo o cliente para além dos aspectos meramente físicos, prosseguiram nos demais encontros. Esta perspectiva de realizar o cuidado, de maneira diferenciada, foi identificada como uma possibilidade que vem ocorrendo de refletir sobre aquilo que se está fazendo, a partir da realização dos primeiros encontros desta prática assistencial, como atesta a fala a seguir.

Esta semana, quando fui aplicar a quimioterapia num paciente, percebi que o mesmo estava muito angustiado. Fiquei conversando com ele por aproximadamente meia hora, antes de realizar a punção. Relatou-me que, além da doença, estava vivenciando problemas familiares. Após a conversa, percebi que o paciente estava menos tenso, quando, então, pude aplicar o tratamento. [...] Depois das reuniões, tem sido melhor, porque percebemos como é importante para o paciente ser bem atendido (Amor Perfeito).

Embora já houvesse o consenso de já estar sendo prestada uma assistência diferenciada, houve a manifestação explícita do reconhecimento da importância dos encontros até então realizados e suas repercussões no trabalho que vêm desenvolvendo. Gastam-se alguns minutos a mais para estar com o cliente, mas ganha-se em qualidade na assistência, representando maior ganho para todos. Refletiu-se que esta é a diferença entre prestar uma assistência com qualidade ou, simplesmente, realizada de forma mecânica, desconsiderando o cliente como um ser semelhante a nós, que necessita, também, de atenção, de diálogo, de carinho. Nesse processo reflexivo, emergiu, ainda, que o atendimento diferenciado ao cliente pode ser prestado por qualquer membro da equipe, desde aquele que realiza as funções mais elementares até aquele que realiza as mais complexas. Por exemplo, à medida que quem realiza a limpeza do ambiente demonstrar sua disponibilidade ao cliente, diante de suas necessidades, estará contribuindo para a melhoria da assistência prestada a este mesmo cliente. Daí porque são importantes o diálogo e a interação, em que as pessoas ouvem, riem, choram, contemplam, participam do dia-a-dia demonstrando, cada um à sua maneira, sensibilidade à importância de cada um na assistência ${ }^{(7)}$. Esta possibilidade de ajuda mútua, de união do grupo está contemplada na fala que se segue.

Eu acho que, de agora em diante, vai melhorar mais do que está. Acho que estamos mais unidos, fazemos uns pelos outros, ajudando uns aos outros [...] Eu gosto muito do meu trabalho, tenho muito amor ao serviço. Nós somos uma pequena família (Rosa).

A equipe de trabalho da unidade de oncologia, mesmo sendo constituída de pessoas com diferentes saberes, valores e histórias de vida, neste momento, vem convergindo seu interesse em refletir, cada vez mais, acerca da assistência que vem prestando aos clientes.

Quanto mais tempo passamos juntos, mais unidos vamos ficar. O que percebo como diferença de outros lugares em que já trabalhei é o coleguismo que existe, aqui. Coleguismo mesmo. Quando qualquer um de nós apresenta-se estressado, cansado, sempre tem alguém para ajudar, dizendo: não. Pára ai! Deixa que eu faço! Eu punciono a veia para ti e tu fazes outra coisa. Nos outros lugares, não tem disso. Tu tens que fazer o teu serviço, embora, estejas cansada, angustiada, estressada. Tens que fazer e pronto (Amor Perfeito).

As experiências vividas, durante a realização dessa prática assistencial, apontam para o fortalecimento do grupo como equipe, em que um vai dando suporte ao outro na realização do seu fazer cotidiano, como tão bem exemplifica a seguinte fala.

Aqui, nós somos todos unidos, nos ajudamos uns aos outros, formamos uma família, trabalhamos em paz, o que, às vezes, a gente não tem em casa. Muitas vezes, é domingo e a gente está louca para vir trabalhar (Amor Perfeito).

Esse estar disponível para o outro, significa compartilhar as experiências diárias, enfrentando as incertezas da vida cotidiana, reconhecendo necessidades e lutas do outro como necessidades e lutas próprias, enfim, como parte do processo de vida, como parte do processo de vida em família( ${ }^{(7)}$.

\section{Considerações finais}

Durante o transcorrer do processo de reflexão coletiva com o grupo de trabalho da unidade de oncologia, afloraram sentimentos que não eram percebidos ou, muitas vezes, não manifestados no dia-a-dia de trabalho. Dentre eles, aqueles contemplados nas falas apresentadas, a sensibilidade, o choro incontido, durante os depoimentos de alguns membros do grupo, acerca do significado de seu trabalho na unidade. Embora a assistência humanizada já fosse uma característica percebida como presente no atendimento ao paciente oncológico, a observação calcada no marco referencial construído possibilitou perceberem-se sob uma nova visão, como seres humanos que, através do diálogo intersubjetivo experienciado, podem utilizar seus potenciais para estar melhor. O estabelecimento de uma relação dialógica, um estar disponível, ouvir e falar oportunizaram a troca de conhecimentos, em que a nossa presença autêntica de cuidadores possibilitounos avançar em nossas reflexões.

Constatou-se que os profissionais que trabalham em oncologia estão expostos, no cotidiano do seu trabalho, a situações geradoras de conflitos que, muitas vezes, são transferidos para as relações interpessoais. A partir da teoria humanística, pôde-se interagir melhor com os membros dessa equipe, oferecendo um espaço para o diálogo para que, desta forma, pudessem ser exteriorizados os sentimentos. Acreditamos na importância desta prática tanto para nós, como enfermeiros, quanto para a equipe de trabalho da unidade de oncologia porque reconhecemos que a interação e o diálogo vivo podem ser utilizados como uma prática assistencial, permitindo que se possa estabelecer e atingir objetivos compartilhados.

\section{Referências}

1. Nunes CHP. Relação médico-paciente em cancerologia. Jornal Brasileiro de Psiquiatria, Rio de Janeiro, mai./jun., 1980;29(3):199202.

2. Pessini LBC. Problemas atuais de bioética. $5^{a}$ ed. São Paulo: Edições Loyola; Centro Universitário São Camilo, 1996. 527 p.

3. Fornés VJ. Actitudes del personal sanitário frente al cáncer: un estudio comparativo entre estudiantes y profesionales de enfermería. Granada: Prensa Universitária; 1991. 135 p.

4. Gomes ES, Anselmo MEO, Lunardi Filho, WD. As reuniões de equipe como elemento fundamental na organização do trabalho. Revista Brasileira de Enfermagem, Brasília (DF) 2000 jul/set;53(3):472-80.

5. Soares NV. A problematização dos direitos do cliente como desencadeadora da problematização dos direitos dos profissionais de enfermagem [dissertação de Mestrado em Enfermagem]. Florianópolis (SC): Programa de Pós-graduação em Enfermagem, Universidade Federal de Santa Catarina; 2000. 158 f. 
6. Ministério da Saúde (BR). Secretaria da Saúde. Secretaria Nacional de Assistência à Saúde. Ações de enfermagem para o controle do câncer. Rio de Janeiro: PRO-ONCO; 1995. 240 p. il. p. 135-9.

7. Paterson JG, Zederad LT. Humanistic nursing. New York: National League for Nursing; 1988. 129 p.

8. Minayo MCS. O desfio do conhecimento: pesquisa qualitativa em saúde. $2^{\mathrm{a}}$ ed. São Paulo (SP): HUCITEC-ABRASCO; 1993. 269 p.

9. Oliveira AMN. Compreendendo o significado de vivenciar a doença mental na família - um estudo fenomenológico e hermenêutico. [dissertação de Mestrado em Enfermagem]. Florianópolis (SC): Universidade Federal de Santa Catarina1999. $173 \mathrm{f}$.

10. Hardingham A. Trabalho em equipe. São Paulo: Nobel; 2000. 61 p.

11. Kübler-Ross E. Sobre a morte e o morrer: o que os doentes terminais têm para ensinar a médicos, enfermeiros, religiosos e aos seus próprios parentes. 8ª . ed. São Paulo: Martins Fontes; 1998. 296 p.

12. Frizon G, SILZBACH RC, SILVEIRA, L. A formação acadêmica sobre o processo de morrer e a morte: a percepção de acadêmicos de enfermagem [monografia de Graduação em Enfermagem]. Rio Grande:
Curso de Enfermagem e Obstetrícia, Fundação Universidade Federal do Rio Grande; 2000. 89 f.

13. Lunardi VL. Do poder pastoral ao cuidado de si: a governabilidade na enfermagem [tese de Doutorado em Enfermagem]. Florianópolis (SC): Universidade Federal de Santa Catarina; 1997. $278 \mathrm{f}$.

14. Rockenbach LH. A enfermagem e a humanização do paciente. Revista Brasileira de Enfermagem, Brasília (DF) 1995 jan/mar;38(1):49-54.

15. Azevedo NA. Prática assistencial às famílias de pacientes em tratamento quimioterápico baseado na Teoria de Paterson \& Zderad: parte 1. Texto e Contexto: Enfermagem, Florianópolis (SC) 2000 mai/ ago;9(2):17-27.

16. George JB. Teorias de enfermagem: fundamentos para a prática profissional. Porto Alegre (RS): Artes Médicas; 1993. 338 p. il.

Data de recebimento: 19/10/2002

Data de aprovação: 20/08/2003 